\title{
Aluminium toxicity-induced alterations in the leaf proteome of rice contrasting response towards inculation of plant growth-promoting bacteria
}

\begin{abstract}
Aluminum ( $\mathrm{Al})$ toxicity is one of the primary factors limiting crop production on acid sulfate soils. In the present study, two-dimensional polyacrylamide gel electrophoresis approach (2D-PAGE) was applied to identify Al tolerance, plant growth promotion and separately expressed proteins were determined using mass spectrometry. Seedlings of rice were grown in an acid sulfate soil. Bio-fertilizer containing acid-tolerant and plant growth-promoting bacteria (PGPB) were given alone or in combination with ground magnesium limestone (GML) at $4 \mathrm{t}$ ha-1. Leaf samples were taken at 45 days after transplanting. Results exhibited that the application of bio-fertilizer and GML increased soil $\mathrm{pH}$ and leaf chlorophyll content. Highest plant height, root length and tiller number were observed in the modified treatments. A total of eight different proteins have been identified to be differentially expressed in rice leaf tissues by mass spectrometry analysis that exposed the differential expression of certain vital proteins. The identified proteins were involved in tolerating abiotic stress, disease resistance, oxidation-reduction process and internal plant physiological functions. Results of analyzing multiple protein spots have shown their involvement for the promotion of plant development and reduction of $\mathrm{Al}$ toxicity. The study thus confirms the primary role of PGPB containing bio-fertilizer with GML on growth of rice under Al toxic conditions in acid sulfate soil.
\end{abstract}

Keyword: Growth promotion; Stress; Toxicity; Bio-fertilizer; Stress proteomics 